\title{
A clínica do dentista na Estratégia Saúde da Família: entre a inovação e o conservadorismo
}

\author{
I ${ }^{1}$ Pedro Augusto Thiene Leme, ${ }^{2}$ Rodrigo Almeida Bastos, ${ }^{3}$ Egberto Ribeiro Turato, \\ ${ }^{4}$ Marcelo de Castro Meneghim I
}

Resumo: Objetivou-se compreender com maior grau de aproximação aspectos da relação entre a odontologia e a sociedade por meio da observaçáo direta do cotidiano e do discurso de dentistas membros de equipes da Estratégia Saúde da Família, que discorreram sobre sua terapêutica na área da saúde bucal num novo cenário normativo. Estudo desenvolvido utilizando o Método Clínico-Qualitativo durante o ano de 2016, que partiu do tema "terapêutica da cárie dentária" como assunto disparador para o desenvolvimento das entrevistas, realizadas por meio de roteiro semidirigido de questóes abertas em profundidade, nas próprias unidades de saúde. $\mathrm{O}$ material obtido foi analisado por meio de Análise Qualitativa de Conteúdo. Os resultados evidenciaram configuraçóes de poder provenientes de um modelo odontológico conservador, desfavoráveis ao propósito da Promoção da Saúde, mas apontaram também potencialidades trazidas pelo modelo de Saúde da Família, reveladas por meio da criatividade e reflexividade sobre açóes educativas e desafios que puderam estimular o profissional. Considerou-se, entretanto, que o trabalho do dentista nesse contexto conservou, predominantemente, um modus operandi hegemônico, caracterizado por relaçóes desequilibradas de poder.

> Palavras-chave: saúde bucal; atenção primária à saúde; Programa Saúde da Família; Sistema Único de Saúde; pesquisa qualitativa.

\author{
1 Odontologia Social, Universidade \\ Estadual de Campinas. Piracicaba- \\ SP, Brasil (pedroleme3@gmail.com). \\ ORCID: 0000-0003-3894-3189 \\ 2 Tocoginecologia e Obstetrícia, \\ Universidade Estadual de \\ Campinas. Campinas-SP, Brasil \\ (almeidabastos.rodrigo@gmail.com). \\ ORCID: 0000-0002-6159-8048 \\ ${ }^{3}$ Psicologia Médica e Psiquiatria, \\ Universidade Estadual de \\ Campinas. Campinas-SP, Brasil \\ (erturato@uol.com.br). \\ ORCID: 0000-0002-7857-1482 \\ ${ }^{4}$ Odontologia Social, \\ Universidade Estadual de \\ Campinas. Piracicaba-SP, Brasil \\ (meneghim@fop.unicamp.br). \\ ORCID: 0000-0003-2673-3627
}

Recebido em: 05/03/2018 Revisado em: 15/01/2019 Aprovado em: 22/01/2019 


\section{Introdução}

$\mathrm{Na}$ última década e meia verificou-se, no Sistema Único de Saúde (SUS), aumento do número de equipes de saúde bucal (ESB), com consequente expansão de cobertura populacional, municípios atendidos, financiamento e assistência em rede nos diversos níveis de complexidade (BRASIL, 2017).

Essa mudança avançou sobremaneira a partir do ano de 2004, quando foi criada a Política Nacional de Saúde Bucal (PNSB), intitulada "Brasil Sorridente", consolidando-a como a maior política pública de saúde bucal do planeta (SCHERER; SCHERER, 2015). Durante anos ocorreu, de forma exponencial, a incorporaçáo das ESB na Estratégia de Saúde da Família (ESF) (AQUILANTE; ACIOLE, 2015). O Brasil é um dos poucos países onde a saúde bucal foi incorporada na Atenção Básica $(\mathrm{AB})$, sendo experiência singular no contexto global.

A PNSB se propôs também a reconfigurar o processo de trabalho da odontologia na $\mathrm{AB}$ a partir de uma perspectiva de promoção da saúde como eixo do cuidado (AQUILANTE; ACIOLE, 2015). A adscrição de clientela e a longitudinalidade seriam ferramentas para um tipo de vínculo próximo e duradouro entre equipe e usuários. Assim, espera-se da equipe de saúde bucal, sob liderança do cirurgiãodentista (CD), uma prática que se volte mais para o cuidado do que para a execução mecanizada de procedimentos, característica de um modelo hegemônico de odontologia privada (NARVAI, 2006).

A PNSB e o Caderno 17 da Atenção Básica são documentos oficiais que trazem as diretrizes para a atuação do dentista nesse contexto, abordando propostas que enfatizam o papel do acolhimento, consideram a integralidade biopsicossocial, a orientação centrada no paciente, a necessidade da escuta qualificada e o compartilhamento do diagnóstico e de decisão sobre condutas (BRASIL, 2004, 2006).

A promoção da autonomia dos usuários é objetivo declarado nos documentos oficiais que orientam a prática em saúde na Atenção Básica, inclusive naqueles voltados ao campo da saúde bucal, ao lado da própria terapêutica (BRASIL, 2004, 2006, 2012; CAMPOS et al., 2006). Nesse contexto, autonomia pode ser entendida como categoria indissociável da Promoçáo de Saúde, a partir da qual o usuário teria maior capacidade de agir sobre seus determinantes (FLEURY-TEIXEIRA et al., 2008). Outra definiçáo é autonomia como capacidade do sujeito lidar com sua rede de dependências (CAMPOS et al., 2006). A autonomia só pode ser pensada pela 
prerrogativa de que o objeto do trabalho em saúde é o sujeito e não os procedimentos terapêuticos desencarnados do indivíduo (CAMPOS et al., 2006).

No entanto, a despeito dos evidentes progressos estruturais e normativos, os diagnósticos acerca da experiência de implantação das ESB na $A B$ sugerem que as mudanças no trabalho do cirurgião-dentista são tímidas, incipientes, persistindo práticas conservadoras, reprodutoras de modelos tradicionais odontológicos que se restringem ao trabalho manual pouco refletido, da postura apartada deste profissional com relação aos demais membros da equipe de saúde (SCHERER; SCHERER, 2015). Assim, em aspectos gerais, foi apontado que inserir a ESB na ESF não resultou em grandes mudanças práticas no modo de trabalho do dentista (MATTOS et al., 2014).

Segundo a PNSB, $75 \%$ a $85 \%$ da carga horária contratada do CD devem ser dedicadas à assistência clínica (BRASIL, 2004). Assim, durante a maior parte do tempo, seu trabalho se concretiza de forma privada, dentro do consultório, onde desenvolve seu potencial terapêutico e onde acreditamos que seja campo profícuo para implementação de inovações tecnológicas sobre o cuidado (JUNQUEIRA et al., 2017; GRAFF; TOASSI, 2017). No âmbito da assistência individual, implementar o conjunto de princípios e diretrizes oficiais significaria promover o que se chama de ampliação da clínica (GRAFF; TOASSI, 2017).

A investigação proposta sobre esse recorte, portanto, é importante para analisar diretamente como todo o novo ideário manifestado vem se materializando. Poucos estudos se pautaram em métodos científicos que permitissem uma aproximação em detalhes da assistência prestada pelo cirurgião-dentista nesse contexto, a fim de captar as minúcias do enquadre privado de um consultório. Nossa hipótese é a de que o refinamento da investigação nessa direção permitiria identificar entraves nesse cenário e subsidiar inovaçóes na prática do dentista, com vistas à aproximação do paradigma de Promoção de Saúde. O objetivo deste estudo foi compreender a prática nesse contexto a partir da observação direta de consultas e da análise qualitativa do relato de experiências e sentimentos dos dentistas de equipes da Estratégia de Saúde da Família.

\section{Fontes e métodos}

O estudo baseou-se em abordagem qualitativa, refinada pelo Método ClínicoQualitativo, concebido especialmente para lidar com relatos pessoais e confidenciais em enquadres de assistência à saúde, o que permitiu uma íntima aproximação do 
contexto das consultas odontológicas, em busca de sentidos e significados atribuídos pelos profissionais (TURATO, 2003; MINAYO, 2006). Este é o primeiro relato de estudo que utiliza este método para investigar o enquadre clínico odontológico.

O município escolhido possui cerca de 400 mil habitantes predominantemente urbanos e localiza-se no interior do Estado de São Paulo (IBGE, 2016). O estudo foi realizado entre janeiro e outubro de 2016. O local foi selecionado de acordo com os critérios de disponibilidade do pesquisador, por possuir consolidada inserção das ESB na ESF, implantadas no município a partir de 2007, e por contar com profissionais contratados por $40 \mathrm{~h}$ semanais por meio de concurso público, conforme preconizado pelas diretrizes (BRASIL, 2004).

Os dentistas foram contatados, inicialmente, por meio de e-mail, contendo breve apresentação do pesquisador, explicação sobre a pesquisa e o convite a participar. Nos casos de aceite, foram combinados os dias para as visitas nas USF, onde foram apresentados ao Termo de Consentimento Livre e Esclarecido (TCLE) e, tendo sido obtido o consentimento formal, iniciadas as observaçóes.

$\mathrm{Na}$ primeira etapa, denominada aculturaçâa, foi estabelecido contato com os habituais do ambiente com o objetivo de assimilar ideias e costumes próprios daquele local a partir da observação direta. Buscou-se a interação entre o pesquisador, os futuros entrevistados e o recorte de objeto (o contexto do atendimento clínico durante a rotina própria do serviço). Foram observadas e anotadas livremente as características gerais e os valores próprios daquela microcultura, registradas as percepçóes do pesquisador sobre as formas de pensar, falar e agir, dentro e fora das consultas.

Além das anotaçóes, nessa etapa foram obtidos subsídios para o aperfeiçoamento do roteiro semidirigido de questôes abertas, que foi usado para as entrevistas, bem como foi buscado o estabelecimento de uma relação de maior confiança junto aos sujeitos da pesquisa, fundamental para que os entrevistados se sentissem confortáveis em expor livremente suas perspectivas nas entrevistas. A aculturação foi realizada por meio de visitas de 2 a 3 horas em cada uma das 10 USF visitadas. O tempo total despendido nesse processo foi de aproximadamente 30 horas.

Em seguida foram entrevistados 10 cirurgióes dentistas das ESB, amostra por exaustâo, composta pelos profissionais que se enquadraram nos critérios de inclusão: ter cumprido ao menos dois anos na atual função laboral, ter sido admitido por meio de concurso público e consentir formalmente em participar (FONTANELLA et al., 2011). Dos 14 profissionais disponíveis, o primeiro foi excluído da amostra final 
devido ao caráter preliminar da entrevista de aculturação, que serviu para ajustes no roteiro de perguntas, dois optaram por náo participar por motivos pessoais e um não respondeu às tentativas de contato do pesquisador.

As entrevistas foram realizadas nas próprias USF, em local silencioso e reservado, sob presença exclusiva do pesquisador e entrevistado, a partir da questão disparadora: "Eu queria que você falasse como você se sente, o que você pensa, qual é a sua experiência sobre o tratamento de cárie?”. Utilizou-se a doença cárie como assunto disparador uma vez que, segundo Botazzo (2013), é o tema em torno da qual a profissão odontológica justifica a maior parte de seus discursos e práticas, sendo assunto fértil para as entrevistas (BOTAZZO, 2013). Foram utilizadas também perguntas auxiliares que contribuíram para manter os rumos da entrevista dentro do escopo pretendido. Foram gravadas (áudio) e transcritas para posterior análise.

As entrevistas foram conduzidas pelo pesquisador principal: dentista, mestre em saúde coletiva e aluno de doutorado. Não foram necessárias repetiçóes de entrevista com o mesmo participante. Embora o pesquisador não tivesse experiência formal prévia com entrevistas, possuía experiência terapêutica que reunia semelhanças com relação à habilidade para escuta de queixas e angústias. Ademais, durante as reunióes de balizamento do projeto, profissionais das áreas psi (psicólogos e psiquiatras, pesquisadores com experiência no método) orientaram e colaboraram com a preparação do pesquisador. A entrevista de aculturação serviu também como ensaio, e ajustes foram feitos.

Os dados foram tratados por meio da Análise Qualitativa do conteúdo, composta por sete etapas: I - transcrição das entrevistas gravadas; II - leitura flutuante das transcriçốes, tangenciando o texto sem ansiedade de marcar respostas; III elaboração de comentários escritos na margem direita das entrevistas transcritas; IV - categorização e subcategorização, agrupando enunciados dos entrevistados de significação semelhantes formando núcleos de sentido; $\mathrm{V}$ - apresentação e discussão do material a pares, (pesquisadores, membros do LPCQ e coautores); VI - definição das categorias de forma exaustiva e meticulosa, para refinar o material; VII validação final por pares (CAMPOS; TURATO, 2009; FARIA-SCHÜTZER et al., 2015). Foram utilizados softwares básicos para edição de texto.

O projeto foi aprovado pelo Comitê de Ética, conforme a resolução no 466/12, sob o número de CAAE 49524715.6.0000.5418. 


\section{Resultados e Discussão}

As características sociodemográficas e dos serviços foram descritas nos quadros 1 e 2, respectivamente. As privilegiadas condiçôes materiais diferem do cenário de outras localidades e contextos, onde foram relatados problemas de recursos e contratações precárias (SCHERER; SCHERER, 2015; REIS; SCHERER; CARCERERI, 2015; BALDANI et al., 2005; MOURA et al., 2013).

A disposição física do consultório, por sua vez, insinuava aos pacientes conduziremse prontamente à cadeira odontológica, em posição característica de manipulação bucal, já desde a recepção. A interdição de manifestação de subjetividades que o ambiente físico proporcionava era complementada pela atitude dos dentistas, que, não raro, procediam diretamente ao exame bucal, sendo a queixa do usuário secundária. Esta, quando ousava aparecer, era apenas um detalhe sem grande influência sobre o planejamento terapêutico.

Entre as ESB analisadas, foi predominante o uso de anotaçóes em fichas apartadas do prontuário geral da unidade e arquivadas dentro do consultório, compostas pelo odontograma e algumas poucas linhas para redação. O odontograma é um formulário que se vale de um esquema gráfico dos dentes, onde é assinalada a condição encontrada e as faces dentárias que deverão receber distintos tratamentos, com códigos de cores e sinais próprios. Normalmente, os espaços para notação dissertativa são poucos e os profissionais os preenchem com uso abundante de siglas e abreviaçôes.

Essa forma de notação, que privilegia o registro de características físicas dos dentes em detrimento de aspectos gerais sobre a queixa dos pacientes, o seguimento clínico e as próprias patologias - como seria num prontuário clínico comum às outras áreas da saúde -, pode ser interpretada como reflexo de uma concepção de prática odontológica que adota o centramento dentário e a operatória como a priori diagnóstico-terapêutico.

Verificou-se uma estrutura física representativa de uma perspectiva tecnicista, de forma que a disposição dos equipamentos, a atitude profissional durante recepção e escuta, a predileção pelo odontograma e pelo arquivamento próprio, a diferenciação linguística e a mínima comunicação com o restante da equipe materializaram as diversas dimensôes do isolamento da boca, em acordo com o problematizado por Botazzo (2013). Tais características físicas influenciam a comunicação na consulta clínica (BARROS; BOTAZZO, 2011). 
As entrevistas duraram, em média, 40 minutos. A partir da Análise Qualitativa de Conteúdo foram identificadas três categorias, que emergiram dos dados: 1 Aquela lavagem cerebral que a gente tenta fazer - o dentista da ESF como promotor de uma odontologia de mercado no campo do cuidado bucal; 2 - O PSF tira um pouco do mecânico - o modelo de Saúde da Família como desafio estimulante ao profissional; 3 - Eu vou testando um jeitinho diferente - experimentando num novo contexto. Os números precedidos da letra "E", ao final dos trechos discursivos, indicam o código do participante.

\section{Aquela lavagem cerebral que a gente tenta fazer - o dentista da ESF como promotor de uma odontologia de mercado no campo do cuidado bucal}

O conceito de campo, central na teoria do senso prático de Pierre Bourdieu, pode ser entendido como um espaço virtual ou sistema estruturado de posiçôes ocupadas pelos agentes, cuja lógica e necessidades são específicas e irredutíveis aos demais campos, possuidor de regras e desafios próprios, onde se entrecruzam interesses sociais (CATANI et al., 2017). Segundo Bourdieu (2003, p. 119), “[...] em qualquer campo descobriremos uma luta [...] entre o novo que entra e tenta arrombar os ferrolhos do direito de entrada e o dominante que tenta defender o monopólio e excluir a concorrência”. Assim, dentro do que consideramos como o campo do cuidado bucal, destacamos, como eixos estruturantes, a polaridade entre a odontologia de mercado $e$ a saúde bucal enquanto política pública.

Verificou-se que o discurso dos dentistas no contexto estudado é coerente com o polo da odontologia de mercado, fenômeno contraprodutivo às propostas normativas do modelo de Saúde da Família (BRASIL, 2004, 2006). Nesse contexto, tal odontologia opera a partir da noção de que cabe ao dentista conscientizar ou até mesmo fazer lavagem cerebral numa população supostamente leiga ou ignorante:

Mas assim, eu não sei como... Vencer essa barreira, fazer com que eles entendam isso né, conscientizá-los da importância (sobre a percepção da perspectiva odontológica "não ser prioridade" para os pacientes) (E1).

Aquela lavagem cerebral que a gente tenta fazer no paciente mostrando na própria boca dele, pra ver se ele toma jeito e ajuda no tratamento pra ele mesmo (E2).

Assim, prevalecem ideais medicalizantes e coerentes com a necessidade industrial de dar vazão aos produtos de higiene bucal, em nome de um saber odontológico que os dentistas presumem não ser do conhecimento da população. $\mathrm{O}$ dentista, mesmo 
nesse contexto, colabora para uma educação preventivista e voltada ao consumo de produtos e procedimentos. Em verdade, na atualidade e no contexto dos centros urbanos, a experiência sugere serem raros discursos das pessoas acerca de práticas de autocuidado bucal que não sejam provenientes das prescriçôes higiênicas propagadas pela mídia e pelos dentistas, o que é indício do alto grau de medicalização presente neste campo (ILLICH, 1975).

Em consonância a essa perspectiva, a odontologia também “dentariza” seu escopo, isto é, adota os dentes apartados do corpo e da vida como seu objeto. Sua teoria prescinde de função e norma (BOTAZZO, 2006). Tal abstração parece ser mais interessante do ponto de vista mercadológico, pois a extrapolação do campo de atuação para além da fisiopatogenia bucal/geral tem criado espaço fértil para o fomento de novas demandas: hálito mentolado por meio de cremes dentifrícios, enxaguatórios, fios saborizados e chicletes; fetichização em torno de escovas de dentes que seriam de última geração, dentes com tonalidades dependentes de agentes clareadores industrializados; alinhamento dentário por meio de equipamentos ortodônticos; implantes e próteses que envolvem micrometalurgia de alta densidade tecnológica; restaurações invisíveis e com perfeição anatômica, dependentes de polímeros de última geração, dentre outros (TESSER; PEZZATO; SILVA, 2015).

Os discursos revelam uma crença profissional de que a boca e os dentes são prioridades e deveriam nortear os hábitos e condutas salutares, e os pacientes deveriam submeter-se, incondicionalmente, à sua tutela e às suas prescriçóes de consumo (BOTAZZO, 2013):

Como eles recebem? Eles não gostam. Eles não gostam mas acabam ficando, às vezes, um pouco, é... Constrangidos, e náo rebatem muito porque eles sabem... Ah, que eu sou a dentista, ele é o paciente, e eu to tentando dar um tratamento pra ele... E... Eu apenas... Digo que ele tem que ajudar (E2).

Tal atitude reflete a legitimidade das verdades científicas produzidas pela odontologia, nas quais o dentista justifica sua atuação. Ao colocar tais verdades como obrigatoriedades a serem seguidas pelo paciente, acaba empobrecendo sua função terapêutica, pois anula o apoio que poderia ser produzido em ato, de forma singularizada, caso houvesse compartilhamento do espaço de poder. $\mathrm{O}$ acesso à subjetividade, que permitiria a construção de intervençóes efetivas, é, assim, interditado (MARTINS, 2004). 
Os diferentes graus de adesão dos pacientes aos ditames científico-odontológicos levam os dentistas a classificá-los entre "bons" e "maus". Assim, os "bons" pacientes seriam aqueles que, sem muita resistência, colaboram, aderem às prescriçóes higiênicas, dietéticas e "compram" o discurso odontológico, reafirmando seu poder:

As mães que já tem uma saúde bucal boa são mais colaboradoras. Já desde pequeno, desde bebê, faz os hábitos, institui os hábitos corretamente, então a gente tem muito mais facilidade (E7).

Quanto aos "maus" pacientes, verificou-se uma tendência de exclusão, de empobrecimento da clínica, restando uma atuação ainda mais procedimental e distante, justificado pela não adesão às prescriçôes. As orientaçôes normalmente circunscrevemse no trinômio biofilme-açúcar-flúor, passando incólumes às determinações sociais e existenciais sobre as doenças (BOTAZZO, 2013). Assim, com aqueles pacientes aos quais seu discurso não mobiliza interesse ou importância, ou seja, que desautorizam o poder odontológico, não vale a pena "perder muito tempo":

Já consegue perceber mais a diferença entre os pacientes, né, entre aqueles que se importam que vai valer a pena você orientar. Tem aqueles que você ficar passando orientação vai ser perda de tempo (E8).

A gente conversa muito nas reuniôes o que fazer né, com esses pacientes aí que dão muito trabalho. Tem uma turma que acha que tem que deixar, que não tem jeito... Tem uma turma que acha que o paciente "bom" que você tem que se dedicar (E9).

Sobre essa questão, Botazzo (2013) coloca que este trata-se de discurso frequente entre os dentistas dos serviços públicos e que sinaliza uma discriminação de classe, comentando que "Os não ignorantes, os informados, os que consomem, os que têm 'cultura odontológica', isto é, que valorizam a Odontologia, para esses poucos saúde bucal é prioridade liberalmente ofertada com plenitude tecnológica" (BOTAZZO, 2013, p. 65).

É prudente ressaltar que os próprios documentos oficiais que orientam a atuação dos dentistas nesse contexto, embora apresentem intençôes progressistas, trazem contradiçôes que revelam a crise teórico-metodológica para uma nova prática, que de certa forma legitimam a postura verificada nos discursos. O caderno 17 (BRASIL, 2006), por exemplo, aborda antigas concepçóes higienistas ao recomendar sobre " $O$ jeito certo de limpar os dentes”; revela a predileção pela explicação da determinação individual e microbiológica de produção das doenças; insiste em defender uma higiene bucal tecnificada. 
Outro material oficial que corrobora essa perspectiva é a cartilha oficial Mantenha seu sorriso fazendo a higiene bucal corretamente (BRASIL, 2013), que, desde o título, traz rígidas recomendaçóes medicalizantes, com imperativos dietéticos, higiênicos, ilustraçôes cartesianas sobre a anatomia da boca e dos dentes, angulações e movimentos "corretos" da escova de dentes. Chama a atenção a ideia fomentada de que acúmulo de placa bacteriana e cálculo dentário são sinônimos de doenças bucais, sendo atualmente compreendidos como condiçôes naturais e eventualmente presentes mesmo em situaçôes de saúde (KILIAN et al., 2016; KAIDONIS; TOWNSEND, 2016), bem como exageros profiláticos tal qual "escovar os dentes após cada refeição", recomendação proveniente da indústria, constante nas instruçóes de uso dos cremes dentifrícios e não endossada cientificamente.

\section{O PSF tira um pouco do mecânico - o modelo de Saúde da Família como desafio estimulante ao profissional}

Considerando a histórica tradição privada da odontologia de mercado, a inserção do dentista na ESF é um fenômeno original. Trata-se de um cenário institucional e normativo novo para as práticas de trabalho, que tensiona mudanças em seu modus operandi e, consequentemente, gera inéditos significados por parte dos trabalhadores (CHAVES; MIRANDA, 2008). A despeito dos conservadorismos apresentados, puderam ser verificadas diferenças, nesse sentido:

Unidade Básica de Saúde (modelo anterior) acaba sendo mais pauleira, atende mais pa-
cientes porque a área de abrangência é maior. Só que não tem esse envolvimento. Comigo
é ao contrário, eu acabo atendendo menos pacientes e tem mais envolvimento [...]. Me
tira da minha zona de conforto, então eu falo assim, não adianta eu pegar e exigir daquela
criança: quem trouxe aquela criança foi a prima que tem 19. Por que a prima de 19 anos
trouxe? Porque a mãe trabalha o dia inteiro, porque o pai tá preso... O irmão bate nele...
Entấo como é que eu vou pedir pra mãe dessa criança passar fio dental nessa criança? Se
ela trabalha assim, 12, 14 horas por dia, a hora que ela chega a criança já tá dormindo,
náo tem quem cuide, a criança fica o dia inteiro na escola... Então tem assim, é muita
coisa pra eu analisar, né... Isso cansa, cansa bastante... Mas, quando você vê resultado...
Aí compensa (E3).

Embora a ideologia preventivista permaneça aparecendo como pano de fundo, é possível notar que, ao menos, existe uma percepção do "ruído" social que passa a ser considerado no caso clínico. Aparentemente, existe uma ambiguidade de sentimentos, sendo o complexo cenário social algo que desgasta o profissional, mas, 
ao mesmo tempo, constitui-se como um desafio com algum potencial para libertá-lo do automatismo e do tecnicismo.

A multiplicidade de experiências de inserção da ESB na ESF ao redor do país resulta em singularidades que impedem generalizações sobre esse assunto. No entanto, estudos apontam que persistem, de forma geral, importantes diferenças entre o prescrito e o real (SCHERER; SCHERER, 2015; REIS; SCHERER; CARCERERI, 2015).

Neste estudo, dentre diversos achados, o modelo de Saúde da Família demonstrou favorecer, incipientemente, um tipo de trabalho mais integral e diversificado que os modelos anteriores, e isso foi motivador pra alguns profissionais:

Por isso que eu digo que eu não consigo trabalhar diferente, e trabalhar na saúde da família pra mim foi um presente [...]. Eu, eu me formei e eu acho que é isso que me moveu, assim... Né, e por isso que eu acho que foi muito bacana eu vir pro saúde da família. Porque você trabalha num sentido mais amplo, você tá fazendo grupo, você tá fazendo visita domiciliar, você chega lá aquele paciente acamado, família não sabe o que fazer, você vai orientar... Então é muito bacana. Muito bacana. Cê não fica lá no consultório direto, né. Você tem mais coisas pra fazer. Entendeu... Cê tem mais coisas de promoção de saúde pra fazer... (E4).

Aparentemente, gerar motivação ou desmotivação dependeu das cosmovisões dos diferentes profissionais. Assim, os desafios ligados ao contexto social, para alguns, constituiu-se em fator estimulante positivo e, para outros, como fator negativo:

No começo eu ficava mais impressionado. Mas de tanto ver, a gente acaba ficando duro, né? Raramente tem alguma coisa que me surpreende agora (E5).

De acordo com os dados sociodemográficos dos entrevistados (quadro 1), foi verificada uma distribuição heterogênea sobre o tempo de formação e áreas às quais dedicaram formação complementar, embora tenham sido frequentes aqueles que cursaram pós-graduação em Saúde Coletiva ou da Família. Talvez os diferentes ciclos de formação que vivenciaram exerçam influência sobre seus afetos relativos ao trabalho nesse cenário. Espera-se que as recentes reformas fomentadas pelas diretrizes curriculares nacionais proporcionem, aos cursos de graduação, maior competência em formar profissionais afetos às demandas do Sistema Único de Saúde (LEME et al., 2015; BRASIL, 2002). 
Quadro 1. Características sociodemográficas dos dentistas das Unidades de Saúde da Família, 2016

\begin{tabular}{|c|c|}
\hline Idade & $\mathrm{N}$ \\
\hline $30-39$ & 6 \\
\hline $40-49$ & 2 \\
\hline $50 \mathrm{ou}>$ & 2 \\
\hline \multicolumn{2}{|l|}{ Sexo } \\
\hline Feminino & 6 \\
\hline Masculino & 4 \\
\hline \multicolumn{2}{|l|}{ Tipo de Faculdade } \\
\hline Pública & 8 \\
\hline Privada & 2 \\
\hline \multicolumn{2}{|l|}{ Década de graduação } \\
\hline $1980-89$ & 1 \\
\hline $1990-99$ & 3 \\
\hline 2000-09 & 6 \\
\hline \multicolumn{2}{|l|}{ Pós-graduação } \\
\hline Aperfeiçoamento/atualização & 5 \\
\hline Especialização & 6 \\
\hline Mestrado & 5 \\
\hline Doutorado & 2 \\
\hline \multicolumn{2}{|l|}{ Área de concentraçáo } \\
\hline Saúde Coletiva ou da Família & 8 \\
\hline Cirurgia & 4 \\
\hline Ortodontia & 3 \\
\hline Odontopediatria & 2 \\
\hline Outros (period, cariol, dentística, DTM, oclusão) & 4 \\
\hline
\end{tabular}


Quadiro 2. Caracterização geral do contexto, 2016

\begin{tabular}{|l|l|}
\hline Localização das unidades & $\begin{array}{l}\text { Bairros periféricos, USFs adjacentes à comunidade de } \\
\text { moradores. }\end{array}$ \\
\hline Tipo de imóveis & $\begin{array}{l}\text { Construídos para abrigar a USF; poucos adaptados, mas } \\
\text { adequados para a função. }\end{array}$ \\
\hline $\begin{array}{l}\text { Composição geral dos } \\
\text { consultórios odontológicos }\end{array}$ & $\begin{array}{l}\text { Aparelhos de climatização, equipos odontológicos atuais, } \\
\text { mochos, pias, autoclaves, fotopolimerizadores, armários, } \\
\text { instrumental e iluminaçâo. Em geral, em bom estado de } \\
\text { funcionamento. }\end{array}$ \\
\hline Composição da ESB & Modalidade I (Cirurgiáo Dentista + ASB) \\
\hline $\begin{array}{l}\text { Anotação e arquivamento dos } \\
\text { dados dos usuários pela ESB }\end{array}$ & $\begin{array}{l}\text { Predominantemente em prontuário próprio (separado } \\
\text { do prontuário geral e arquivado na própria sala do } \\
\text { consultório) com predileçẫo pelo uso do odontograma. }\end{array}$ \\
\hline Agendamento & $\begin{array}{l}\text { Em algumas USF, as ESB controlavam o agendamento; } \\
\text { em outras, era feito pelo agendamento geral (Agentes } \\
\text { Comunitários de Saúde). }\end{array}$ \\
\hline
\end{tabular}

\section{Eu vou testando um jeitinho diferente - experimentando num novo contexto}

A experiência adquirida pelos dentistas num modelo assistencial que proporciona o vínculo e o acompanhamento longitudinal junto aos usuários parece influenciar sua subjetividade sobre as práticas educativas. Assim, as concepçôes verticais e excessivamente diretivas sobre educação em saúde que portavam, provavelmente cunhadas durante uma formação acadêmica limitada, desconectada da realidade social e pautadas por uma hegemonia cientificista, aparentemente foram questionadas a partir da nova vivência:

O que nós aprendemos, foi "oriente o paciente porque o paciente tem que fazer isso, tem que fazer aquilo" né, é isso que o paciente tem que fazer, então é muito direcionado, muito unilateral, bastante verticalizado, só que eu acho que com o tempo eu percebi, no dia a dia, a gente percebe que muitas vezes não funciona né! (E6).

O fato de o entrevistado conseguir reconhecer as limitaçôes desse tipo de educação em saúde, ainda que não signifique superação de toda a problemática, é um indício de que a imersão naquela realidade pode ter tensionado algum grau de estranhamento, que permitiu reflexão sobre essa prática. 
Adicionalmente, foram relatadas situações nas quais observou-se uma maior sensibilidade perante as singularidades, com a consequente adaptação do saber prévio àquele contexto, sugerindo um amadurecimento promovido pela experiência na ESF:

Eu vou testando, tem coisa assim que aparece diferente e eu vou testando um jeitinho diferente, tem gente que tem que ter uma abordagem diferente, adolescente tem que ter uma abordagem diferente, porque eles não aceitam que ninguém fale o que eles tem que fazer, como eles tem que fazer... Né... Então eu vou aos pouquinhos (E3).

Adolescente também não é difícil, cê pega bem porque você pega pela estética... Né, porque geralmente é uma fase que tá namorando (E4).

A despeito desses aspectos positivos, o conjunto mais amplo dos achados deste estudo corrobora a perspectiva de outros autores de que o desenvolvimento teórico da área de educaçáo em saúde não vem sendo devidamente incorporado nos serviços, onde predomina a prática prescritiva centrada nas mãos do profissional da saúde (SILVA et al., 2010). Porém, o inevitável contato com a realidade social e a longitudinalidade, que favorecem a visualização de resultados de intervençôes a médio e longo prazo, parecem abrir brechas para que o profissional perceba limitaçôes desse tipo de prática.

\section{Considerações finais}

O conteúdo das entrevistas, associado às observaçôes de campo, evidenciou que, de forma geral, foram mantidos aspectos do modus operandi odontológico tradicional dentro da atenção à saúde bucal na ESF no contexto analisado. Os discursos sobre a clínica revelam a persistência de uma configuração de poder desequilibrada, em que a potência do paciente tem poucas oportunidades de se manifestar no processo terapêutico, que sistematicamente é reduzido ao mecanicismo e automatismo em torno dos procedimentos e da prescrição de itens de consumo. Considerando que as principais doenças bucais possuem caráter crônico, não comunicável e, portanto, pouco dependentes dos procedimentos técnicos que são privilegiados no ato clínico, a resolutividade é comprometida desde o ponto de partida. As narrativas evidenciam, sobretudo, a naturalização de prescriçôes preventivistas cuja cientificidade legitima e oculta, a um só tempo, sua origem infraestrutural e a baixa compreensão sobre os determinantes sociais de saúde.

Por outro lado, como aspectos positivos, os discursos revelam que o contexto social complexo que envolve a ESF serviu como desafio para alguns dos profissionais, 
provavelmente por demandar outros tipos de habilidades do dentista, quebrando incipientemente o automatismo e a regularidade dos modelos de atenção prévios. Além disso, com relação ao campo da educação em saúde, alguns profissionais perceberam limites das práticas prescritivas tradicionais, talvez devido ao fato de o modelo proporcionar um contato mais próximo e duradouro com os usuários sem que, no entanto, demonstrem apresentar um suficiente arsenal de ferramentas para superar essa lacuna.

A implementação da atenção em Saúde Bucal no Brasil é importante conquista de proteção social, e as críticas e desafios a serem enfrentados só podem ser apontados devido ao fato de a experiência ter se materializado, superando parcialmente um histórico de exclusão e de falta de acesso da população aos serviços de saúde bucal. Ressalta-se que existe urgência por novos saberes teórico-metodológicos que avancem sobre a ciência odontológica intramuros e laboratorial, advogando-se pela necessidade de a Saúde Coletiva influenciar essa agenda, inclusive no que diz respeito à clínica, historicamente marginalizada no campo científico. Isso não significa minimizar a produção científica odontológica, mas reconhecer seus limites epistemológicos. ${ }^{1}$

\section{Referências}

AQUILANTE, A. G.; ACIOLE, G. G. O cuidado em saúde bucal após a Política Nacional de Saúde Bucal - "Brasil Sorridente": um estudo de caso. Cien Saúde Colet. Rio de Janeiro, v. 20, n. 1, p. 239-48, 2015.

BALDANI, M. H. et al. A inclusão da Odontologia no Programa Saúde da Família no Estado do Paraná, Brasil. Cad Saúde Pública. Sáo Paulo, v. 21, n. 2, p. 1026-35, 2005.

BARROS, R. S.; BOTAZZO, C. Subjetividade e clínica na atenção básica: narrativas, histórias de vida e realidade social. Cien Saúde Colet. Rio de Janeiro, v. 16, n. 11, p. 4337-48, 2011.

BOTAZZO, C. Diálogos sobre a boca. São Paulo: Hucitec, 2013. 380 p.

. Sobre a bucalidade: notas para a pesquisa e contribuição ao debate. Cien Saúde Colet. Rio de Janeiro, v. 11, n. 1, p. 7-17, 2006.

BOURDIEU, P. Questóes de sociologia. Lisboa, 2003. 290 p.

BRASIL. Conselho Nacional de Educaçấo. Câmara de Educaçáo Superior. Resolução CNE/ CES 3, de 19 de fevereiro de 2002. Institui Diretrizes Curriculares Nacionais do Curso de Graduação em Odontologia. Brasília: Diário Oficial da Uniāo, 4 mar. 2002. 
- Ministério da Saúde. Diretrizes da Politica Nacional de Saúde Bucal. Secretaria de Atenção à Saúde. Departamento de Atenção Básica. Coordenação Nacional de Saúde Bucal. Brasília: Ministério da Saúde, 2004.

. Ministério da Saúde. Mantenha seu sorriso: fazendo a higiene bucal corretamente. Brasília: Ministério da Saúde, 2013.

- Ministério da Saúde. Política Nacional de Atenção Básica. Brasília: Ministério da Saúde, 2012.

. Ministério da Saúde. Saúde bucal. Cadernos de Atenção Básica. Brasília: Ministério da Saúde, n. 17, 2006. (Série A - Normas e Manuais Técnicos).

. Sala de Apoio à Gestão Estratégica. Departamento de Atenção Básica. Ministério da Saúde. Disponível em: <http://dab.saude.gov.br/portaldab/sala_apoio_gestao_estrategica.php>. Acesso em: 1 jan. 2017.

CAMPOS, C. J.; TURATO, E. R. Content analysis in studies using the clinical-qualitative method: application and perspectives. Rev Lat Am Enfermagem. Ribeirão Preto, v. 17, n. 2, p. 259-64, 2009.

CAMPOS, G et al. Tratado de Saúde Coletiva. Rio de Janeiro: Hucitec/Fiocruz, 2006. 880 p.

CATANI, A. M. et al. Vocabulário Bourdieu. Belo Horizonte: Autêntica Editora, 2017. 400 p.

CHAVES, M. C.; MIRANDA, A. S. Discursos de cirurgiōes-dentistas do Programa Saúde da Família: crise e mudança de habitus na Saúde Pública. Interface comun. saúde educ. Botucatu, v. 12, n. 24, p. 153-67, 2008.

FARIA-SCHÜTZER, D. B. et al. Emotional Experiences of Obese Women with Adequate Gestational Weight Variation: A Qualitative Study. PLoS One. San Francisco, v. 10, n. 11, 2015. FLEURY-TEIXEIRA, P. et al. Autonomia como categoria central no conceito de promoção de saúde. Cien Saúde Colet. Rio de Janeiro, v. 13, n. 2, p. 2115-22, 2008.

FONTANELLA, B. J. B. et al. Amostragem em pesquisas qualitativas: proposta de procedimentos para constatar saturação teórica. Cad. Saúde Pública. São Paulo, v. 27, n. 2, p. 389-394, 2011.

GRAFF, V. A.; TOASSI, R. F. C. Produção do cuidado em saúde com foco na clínica ampliada: um debate necessário na formação em odontologia. Rev. Abeno. Londrina, v. 17, n. 4, p. 63-72, 2017.

INSTITUTO BRASILEIRO DE GEOGRAFIA E ESTATÍSTICA. Cidades Brasil, 2016. Sintese dos dados do município. Disponível em: <http://www.cidades.ibge.gov.br/v3/cidades/ municipio/3538709>. 
ILLICH, I. A expropriação da saúde. Nêmesis da Medicina. Rio de Janeiro: Nova Fronteira, 1975. $164 \mathrm{p}$.

JUNQUEIRA, S. R. et al. Projeto Inovação na Produção do Cuidado em Saúde Bucal. Rev. Grad. USP. São Paulo, v. 2, n. 2, p. 149-156, 2017.

KAIDONIS, J.; TOWNSEND, G. The 'sialo-microbial-dental complex' in oral health and disease. Ann Anat, v. 203, n. 1, p. 85-9, 2016.

KILIAN, M. et al. The oral microbiome - an update for oral healthcare professionals. BDJ Open, v. 221, n. 1, p. 657-666, 2016.

LEME, P. A. et al. Perspectivas de graduandos em odontologia acerca das experiências na atenção básica para sua formação em saúde. Cien Saúde Colet. Rio de Janeiro, v. 20, n. 4, p. 1255-65, 2015.

MARTINS, A. Biopolítica: o poder médico e a autonomia do paciente em uma nova concepção de saúde. Interface comun. saúde educ. Botucatu, v. 8, n. 14, p. 21-32, 2004.

MATTOS, G. C. M. et al. A inclusão da equipe de saúde bucal na Estratégia Saúde da Família: entraves, avanços e desafios. Cien Saúde Colet. Rio de Janeiro, v. 19, n. 2, p. 373-82, 2014.

MINAYO, M. C. S. O Desafio do conhecimento, pesquisa qualitativa em saúde. São Paulo:Rio de Janeiro; Hucitec:ABRASCO, 2006. 406 p.

MOURA, M. S. et al. Saúde bucal na estratégia de saúde da família em um colegiado gestor regional do estado do Piauí. Cien Saúde Colet. Rio de Janeiro, v. 18, n. 2, p. 471-80, 2013.

NARVAI, P. C. Saúde bucal coletiva: caminhos da odontologia sanitária à bucalidade. Rev Saúde Pública. São Paulo, v. 40, n. spe, p. 141-7, 2006.

REIS, W. G.; SCHERER, M. D. D. A.; CARCERERI, D. L. O trabalho do CirurgiãoDentista na Atenção Primária à Saúde: entre o prescrito e o real. Saúde debate. Rio de Janeiro, v. 39, n. 104, p. 56-64, 2015.

SCHERER, C. I.; SCHERER, M. D. Avanços e desafios da saúde bucal após uma década de Programa Brasil Sorridente. Rev. Saúde Pública. São Paulo, v. 49, n. 98, 2015.

SILVA, C. M. D. C. et al. Educação em saúde: uma reflexão histórica de suas práticas. Cien Saúde Colet. Rio de Janeiro, v. 15, n. 5, p. 2539-50, 2010.

TESSER, C. D.; PEZZATO, L. M.; SILVA, E. N. Medicalização social e odontologia: possíveis aproximações. Saude soc. São Paulo, v. 24, n. 4, p. 1349-1361, 2015.

TURATO, E. R. Tratado da metodologia da pesquisa clínico-qualitativa: construção teóricoepistemológica, discussão comparada e aplicação nas áreas da saúde e humanas. Petrópolis: Vozes, 2003. 685 p. 


\section{Nota}

${ }^{1}$ P. A. T. Leme contribuiu substancialmente para a concepçấo e planejamento, análise e interpretação dos dados, elaboração do rascunho e aprovação da versão final do manuscrito. R. A. Bastos contribuiu substancialmente para a análise e interpretação dos dados, revisão crítica do conteúdo e aprovação da versão final do manuscrito. E. R. Turato contribuiu substancialmente para a concepçáo e planejamento, revisão crítica do conteúdo e aprovação da versão final do manuscrito. M. de C. Meneghim contribuiu substancialmente para a concepção e planejamento, análise e interpretação dos dados, revisão crítica do conteúdo e aprovação da versão final do manuscrito. 


\section{Abstract}

\section{The dentist's clinical practice in the Family Health Strategy: between innovation and conservatism}

The aim was to better understand aspects of the relationship between dentistry and society through the direct observation of the daily service and the discourse of dentists members of the Family Health Strategy (Primary Care) teams, who discussed their oral health therapy in a new regulatory scenario. A study developed using the Clinical-Qualitative Method during the year 2016, starting from the theme "dental caries therapy" as a triggering subject for the development of the interviews, carried out by a semi-structured questionnaire of in-depth open questions in the units of health. The material obtained was analyzed through Qualitative Content Analysis. The results showed power settings descended from a conservative dental point of view, unfavorable to the purposes of Health Promotion paradigm, but also pointed to potential brought by the Family Health model, revealed through creativity and reflexivity about educational actions and challenges that could stimulate the professional. It was considered, however, that the work of the dentist in this context retained predominantly a hegemonic modus operandi, characterized by unbalanced relations of power.

> Keywords: oral health; primary health care; Family Health Program; Unified Health System, qualitative research. 